\title{
Cone Beam Computed Tomography in Endodontics
}

\author{
Conor DURACK \\ Shanon PATEL
}

Unit of Endodontology, Department of Conservative Dentistry, Dental Institute, King's College London, London, UK

\begin{abstract}
Cone beam computed tomography (CBCT) is a contemporary, radiological imaging system designed specifically for use on the maxillofacial skeleton. The system overcomes many of the limitations of conventional radiography by producing undistorted, three-dimensional images of the area under examination. These properties make this form of imaging particularly suitable for use in endodontics. The clinician can obtain an enhanced appreciation of the anatomy being assessed, leading to an improvement in the detection of endodontic disease and resulting in more effective treatment planning. In addition, CBCT operates with a significantly lower effective radiation dose when compared with conventional computed tomography (CT). The purpose of this paper is to review the current literature relating to the limitations and potential applications of CBCT in endodontic practice.
\end{abstract}

Key Words: Cone beam computed tomography, conventional radiography, Endodontics, diagnosis, management.

\section{INTRODUCTION}

Successful management of endodontic problems is reliant on diagnostic imaging techniques to provide critical information about the teeth under investigation, and their surrounding anatomy. Since its inception, conventional radiography has remained the mainstay of imaging in Endodontics. In recent decades, however, advances in medical imaging have been applied, with varying success, to the various dental disciplines. Among the specific imaging techniques, which have been researched as potential diagnostic and treatment planning tools in Endodontics, are digital subtraction radiology (DSR), tuned aperture computed tomography (TACT), ultrasound (US), magnetic resonance imaging (MRI) and computed tomography (CT) (1). These imaging techniques have been slow to gain acceptance in Endodontics, for an array of different reasons. As such, conventional radiography, despite its inherent limitations, remains the default imaging system in the field. However, the development of cone beam computed tomography (CBCT) has highlighted the inadequacies of conventional radiography when assessing the unique anatomy of the maxillofacial skeleton (1). This threedimensional imaging system has been the subject of unparalleled levels of independent research in dental imaging. A significant portion of this published research has been specific to Endodontics, where the findings have been emphatic.

This paper reviews the fundamentals of $\mathrm{CBCT}$ and presents the applications of this imaging system in contemporary endodontic practice.

\section{LIMITATIONS OF CONVENTIONAL RADIOGRAPHIC IMAGING}

The limitations of conventional radiographic imaging in dentistry have been well reported on. The reduced diagnostic yield of conventional radiography can be attributed to several factors (1), which are discussed as follows.

\section{Compression of Three-Dimensional Structures}

Conventional radiography compresses threedimensional structures on to a two-dimensional image. The radiograph provides a visualization of the anatomy under examination in the mesiodistal plane, whilst affording very little appreciation of structures in the third (buccolingual) dimension (1).

The compression of three-dimensional anatomy associated with conventional radiography often

Correspondence: Dr. Conor Durack, Department of Conservative Dentistry, Floor 25 Guy’s Hospital, Great Maze Pond, SE1 9RT London, UK. Tel: 0044 (0) 20 71883874. email: conordurack1@hotmail.com 
precludes an accurate appreciation of the spatial relationship of a tooth's roots to the surrounding anatomy and any associated periapical lesions (2). Furthermore, anatomical complexities and diseases affecting the dental hard tissues, such as resorption (3), as well as operative procedural errors (4) may not be appreciated if more accurate imaging are not used. Diagnostic performance is consequently impaired $(5,6)$. Parallax radiographic images with changes in the horizontal angulation of the X-ray beam, in relation to the area of interest, have been shown to contribute to an improved depth of perception and appreciation of spatial relationship in dental radiographic imaging (7).

\section{Geometric Distortion}

Intraoral periapical radiographs should be taken using a paralleling technique. This provides a more accurate geometric representation of the object of interest than do techniques such as the "bisecting angle" method (8-10). To obtain paralleled images, the image receptor should be positioned parallel to the tooth under investigation, and the X-ray beam should be perpendicular to both (11). The anatomical confines of the oral cavity mean that this ideal is seldom achieved, despite the availability of paralleling film holders. The use of rigid image receptors, such as those used with charged couple device (CCD) digital systems, adds to the difficulty. A minimum 5\% magnification of the object being radiographed can be expected in the final image, even when the paralleling procedure is executed perfectly (12). This is due to the unavoidable separation between the image receptor and the object, and the divergent nature of the $\mathrm{X}$-ray beam during imaging. The ultimate result is that the geometry of the area being assessed is rarely reproduced with complete accuracy using conventional intraoral radiography (1).

\section{Anatomical Noise}

Anatomy in, or projected over, the area of interest during conventional radiographic imaging may impair visualization of the object under investigation, and complicate interpretation of the radiograph. These anatomical interferences can vary in radiodensity and are referred to as anatomical noise $(13,14)$. Anatomical noise caused by features of overlying alveolar bone such as the cortical plate, trabeculae and marrow spaces have been specifically reported as complicating factors in the accurate detection of simulated periapical lesions (15-17) and external root resorption (ERR) $(18,19)$.

\section{Temporal Perspectives}

Intraoral periapical radiographs of a particular area or tooth need to be compared over time to assess the development or progression of a disease. The radiographs should be standardized with respect to the X-ray beam angle, the object to image receptor distance and all of the radiation exposure parameters. Furthermore, the positional relationship between the image receptor and the object should be reproduced for each radiograph. In this manner all variables, other than the one under investigation i.e. the disease process, are kept constant (20). Poorly-standardized radiographs may result in a misinterpretation of disease onset or progression. This is particularly salient in the assessment of ERR, which can commence and progress rapidly (3). Even when customized bite blocks attached to the paralleling device are used to take serial radiographs, the images will never be identical (21).

\section{CONE BEAM COMPUTED TOMOGRAPHY}

\section{Background}

Cone beam computed tomography (CBCT) is a contemporary, three-dimensional, diagnostic imaging system designed specifically for use on the maxillofacial skeleton $(22,23)$. It has its origins in conventional medical CT. However, CBCT differs from the latter in a number of fundamental ways; differences which optimize its suitability for dental imaging.

\section{Image Acquisition and Reconstruction}

The CBCT hardware consists of an X-ray source and detector, or sensor, mounted on a rotating gantry. During imaging, a cone-shaped X-ray beam is emitted from the X-ray source and is directed through the area of interest in the patient's maxillofacial skeleton. Having passed through the area of interest, the beam is projected on to the X-ray detector, as both it and the X-ray source rotate synchronously $180^{\circ}-360^{\circ}$ around the patient's head, in a single sweep. The scan time typically ranges from 10-40 s, depending on the equipment and exposure parameters employed. However, many CBCT systems employ a pulsatile X-ray beam and with these systems 
the actual patient exposure time can be as low as $2-5 \mathrm{~s}$ (24). During the exposure sequence, hundreds of basis images (projection images) of the area of interest are acquired. The projection images are then reconstructed, using sophisticated software, to produce a cylindrical or spherical volume of data, called the field of view (FOV). Each projection image is comprised of up to and in excess of $216,124(512 \times 512)$ pixels. The reconstructed, three-dimensional data set will comprise $512^{3}$ threedimensional pixels, or voxels (24). Reconstructed CBCT images can be displayed in a variety of ways. A commonly used option is for the images of the area of interest to be displayed, simultaneously, in the three orthogonal planes (axial, sagittal and coronal), affording the clinician a truly three-dimensional view of the area of interest.

\section{Classification of CBCT}

Cone beam computed tomography systems are most commonly classified according to the dimensions of their FOV or scan volume. The following categorization has been proposed (25):

Small volume (also referred to as focused, small field, limited field or limited volume) systems have a maximum scan volume height of $5 \mathrm{~cm}$. Single arch CBCT scans have a FOV height of 5-7 cm within one arch; inter-arch CBCT scans have a FOV with a height of 7-10 cm; maxillofacial CBCT scans have a FOV height ranging from $10-15 \mathrm{~cm}$; and craniofacial CBCT have a FOV height in excess of $15 \mathrm{~cm}$.

Less popular methods of classifying CBCT systems are based on the patient position during the scan (supine, sitting or standing) and the functionality of the systems; some systems are multimodal and have a digital panoramic tomograph (DPT) function (25).

\section{Effective Dose of CBCT}

The radiation dose produced by a given CBCT system is dependent on a number of factors. The nature of the X-ray beam i.e. whether it is continuous or pulsatile, the degree of rotation of the X-ray source and detector and the size of the FOV will all have a bearing on the radiation dose. So too will the amount and type of beam filtration and the $\mathrm{kV}, \mathrm{mA}$ and voxel size settings. Collectively, these factors are referred to as the exposure parameters. Some exposure parameters such as beam filtration, the nature of the X-ray beam and, to an extent, FOV are specific to a particular system, whilst factors such as the degree of X-ray source rotation, $\mathrm{kV}$ and $\mathrm{mA}$ can be altered on most systems (25).

However, some human tissues are more sensitive to ionizing radiation than others. Cone beam computed tomography scans with different FOV will irradiate different tissues. In order to gain a meaningful appreciation of the biological effect that the radiation has on the patient, human tissues are weighted according to their radiation sensitivity. The effective dose takes into account the radiation dose produced by the imaging system and the radiation sensitivity of the tissues that the X-ray beam is passing through during the exposure sequence. Effective dose is measured in Sieverts (Sv) and is often expressed in micro Sieverts (Sv), as the figures involved are so low (26).

Small volume CBCT scanners are well suited for use in Endodontics as the area of interest can easily be captured by their smaller FOV. Loubele et al. (27) measured the effective doses from one particular small volume CBCT scanner (Accuitomo 3D; J. Morita Corporation, Kyoto, Japan) when different areas of the maxillofacial skeleton were imaged. The scanner had a cylindrical FOV which was $3 \mathrm{~cm}$ high and $4 \mathrm{~cm}$ wide and the scans involved $360^{\circ}$ of rotation of the X-ray source and detector. The effective doses associated with CBCT scans, using this device, ranged from $13 \mu \mathrm{Sv}$ (anterior mandible) to $44 \mu \mathrm{Sv}$ (maxillary canine/premolar region) respectively (27). By comparison, the effective dose of a single intraoral periapical radiograph ranges from 1-5 $\mu \mathrm{Sv}$, depending on the area of interest and the type of beam collimation employed (28). However, up until 2011, very little data existed pertaining to the effect of altering the exposure parameters (with the exception of voxel size settings) of CBCT scans on the diagnostic yield of the images produced and the related effective radiation doses to the patient. Scans tended to be taken using the CBCT hardware's manufacturer's settings as was the case in the radiation dose study mentioned previously (27). Ex vivo evidence now exists to suggest that by altering the degree of rotation of the $\mathrm{X}$-ray source and detector from $360^{\circ}$ to $180^{\circ}$ and therefore away from the manufacturer's settings, the effective dose to the patient is potentially halved without a reduction in diagnostic yield $(3,29)$. Of further encouragement to the application of CBCT in Endodontics is the fact that these studies were examining the diagnostic accuracy of CBCT in the detection of the most common endodontic diseases, namely external root resorption (3) and apical periodontitis (29). 


\section{Advantages of $C B C T$}

Cone beam computed tomography overcomes the limitations of conventional radiography. The production of three-dimensional images allows a comprehensive appreciation of the anatomy, and its spatial relationship to the tissue destruction caused by the pathosis under examination. Slices of the volumetric data can be chosen by the clinician and viewed in all the orthogonal planes and in non-orthogonal planes. Anatomical noise can, therefore, be easily eliminated (30). Cone beam computed tomography voxels are isotropic ensuring that the images produced are geometrically accurate and image measurements, in any plane, are free from distortion (31). Indeed, the three-dimensional geometric accuracy of CBCT has been confirmed repeatedly $(32,33)$. In contrast, CT images are comprised of anisotropic voxels, which limits the geometric accuracy of this form of imaging (24).

The main advantages of CBCT over CT are the reduced patient exposure to ionizing radiation $(22,23)$ and a superior image quality with respect to dental hard tissue (34-36) and bone (37) assessment. As the CBCT $\mathrm{X}$-ray beam can be pulsatile the patient is often exposed to radiation for only a small portion of the overall scan time. In addition, the X-ray source can be collimated such that only the area of interest is radiated, producing a specific volume of data (FOV) appropriate and relevant to the patient's needs. The smaller the FOV the less the radiation exposure is to the patient (38). The degree of rotation of the X-ray source around the patients head can also be modified. Greater numbers of projection images are produced with higher degrees of rotation (25). Theoretically, this may be accompanied by an increased diagnostic yield, but at the expense of greater radiation exposure to the patient.

The software necessary for CBCT data reconstruction can be run on personal computers, potentiating its use as a chairside diagnostic and treatment planning tool (25). In addition, multiple slices can be scrolled through in real time producing dynamic images. Cursor driven measurements allow dimensional assessments to be made, again in real-time. In addition, basic image manipulations are possible. Window levels can be adjusted, specific areas can be magnified and annotations can be added $(25,30)$. Surface rendering software is also available (24).

The scan times achievable with CBCT are short and comparable with panoramic radiography. This is beneficial in that the likelihood of patient movement during the scan is less. In addition, the CBCT hardware is much smaller and less expensive than CT machines. Therefore, $\mathrm{CBCT}$ is well suited to use in dental practice (24).

\section{Limitations of $C B C T$}

Cone beam computed tomography imaging is sometimes affected by radiographic artifacts related to the X-ray beam. When the CBCT X-ray beam encounters an object of very high density, such as enamel or metallic restorations, lower energy photons in the beam are absorbed by the structure, in preference to higher energy photons. The result is that the mean energy of the X-ray beam increases. This is called 'beam hardening' and the phenomenon produces two types of artifact: distortion of metallic structures, called 'cupping artifact', and the appearance of streaks and dark bands between two dense
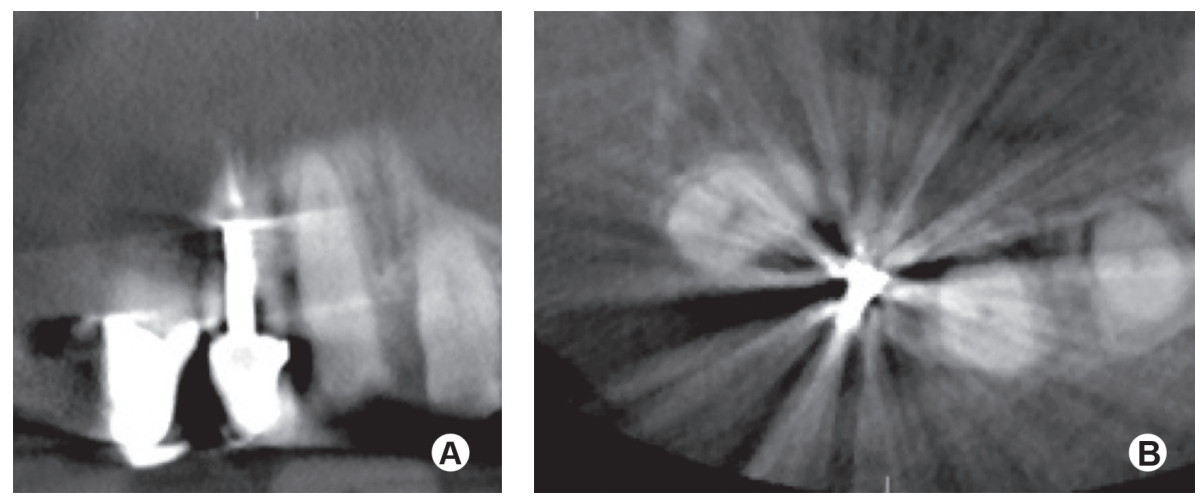

Figure 1. (a,b) Coronal (a) and axial (b) CBCT slices through a maxillary left central incisor tooth restored with a post-retained crown. Beam hardening caused by the metallic post has resulted in the appearance of streaks and bands, impairing the quality of the images. 
structures (30) (Fig. 1). These artifacts can reduce the diagnostic yield of the images $(39,40)$. Furthermore, patient movement during the scan can adversely affect the sharpness of the final image (30).

The spatial resolution of CBCT is approximately 2 line pairs per $\mathrm{mm}^{-1}$ (41) and is inferior to conventional dental radiography, which has a spatial resolution in the order of 15-20 line pairs per $\mathrm{mm}^{-1}$ (42). In addition, the contrast resolution of CBCT is poor (30) and is inferior to that of CT, which has a high contrast resolution (43).

As discussed, the effective dose of CBCT is generally higher than that of conventional intraoral radiography. However, this gap is continuously narrowing, and in certain clinical scenarios the effective dose of $\mathrm{CBCT}$ will approach that of periapical radiography.

\section{Applications of CBCT in Endodontic Practice}

Cone beam computed tomography overcomes the limitations of conventional radiography. Therefore, the potential benefits of this imaging system in Endodontics, where the anatomy being assessed is complex, are vast. These advantages, combined with the reduced cost and size of CBCT hardware and scans when compared with conventional $\mathrm{CT}$, have seen an increased uptake in this form of imaging in dental practices in recent years (31). With CBCT becoming an ever more accessible component of the endodontist's armamentarium, it is important to be aware of the applications of this form of imaging method in managing endodontic problems.

\section{Detection of Apical Periodontitis}

Cone beam computed tomography is significantly more sensitive than conventional radiography in the detection of apical periodontitis in humans (40). Periapical bone destruction associated with endodontic infection can be identified using CBCT before evidence of the existence of these lesions presents itself on conventional radiographs $(44,45)$ (Fig. 2). LofthagHansen et al. (39) compared the prevalence of apical periodontitis in maxillary and mandibular posterior teeth in a small human population using conventional periapical radiography and $\mathrm{CBCT}$. They found that CBCT detected $62 \%$ more periapical lesions than conventional radiographs, although the assessment of the subject teeth was increased by parallax views in the latter technique. These findings were corroborated in similar studies with much larger sample sizes $(40,46)$.

The findings of these human in vivo experiments have been validated using ex vivo human (47) and animal models (48) in which periapical lesions were artificially created at verified healthy sites. Patel et al. (47) demonstrated that the sensitivity of CBCT in the detection of simulated lesions of apical periodontitis was $1.0(100 \%$ accuracy). Intraoral periapical radiographs, on the other hand, detected the simulated lesions in only $24.8 \%$ of the cases - a statistically significant difference. Of further encouragement is recent evidence that the
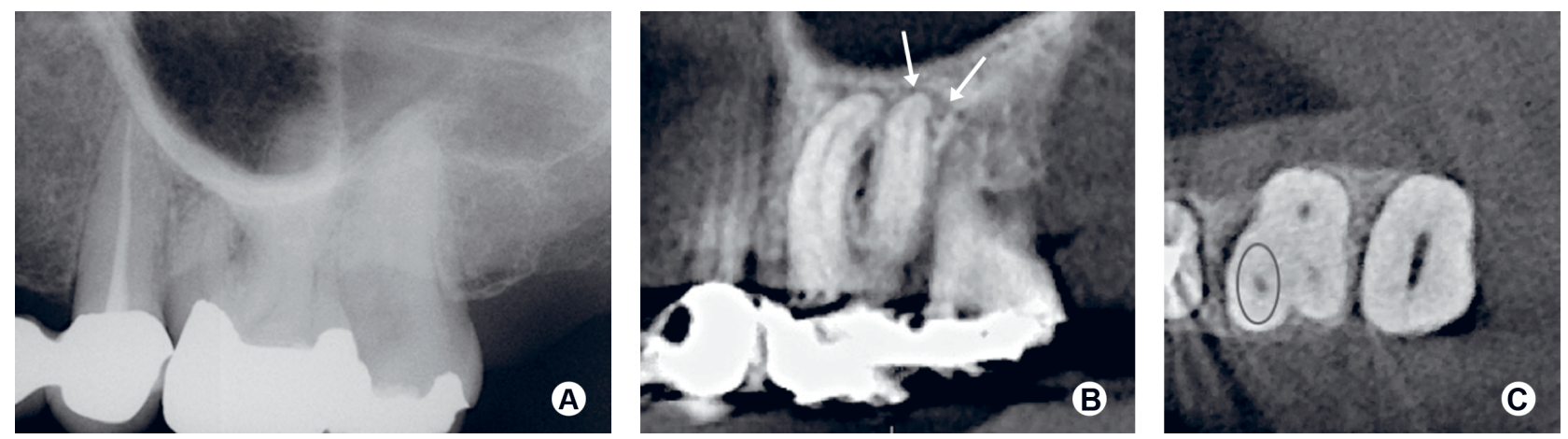

Figure 2. (a) Periapical radiograph of a symptomatic maxillary left first molar tooth. There is no evidence of a periapical radiolucency associated with the roots of this tooth. (b) Sagittal CBCT slice through the same tooth demonstrating the periapical bone destruction (white arrows) not evident on the periapical radiograph. Anatomical noise, caused in part by the zygomatic buttress, has obscured the area of interest on the periapical radiograph, reducing the diagnostic yield. Compression of this three-dimensional structure on the periapical radiograph, is also partly responsible. By examining the axial CBCT slices (c) of the tooth, it is evident that only one MB canal (circle) is present in the tooth. Advanced knowledge of this eradicates the need for excessive dentine removal to search for a supplemental canal. 
same diagnostic performance can be expected when certain exposure parameters are adjusted to reduce the patient radiation dose. Lennon et al. (29), using similar experimental materials and methods to that of Patel et al. (47), examined the effect of altering the arc of rotation of the same CBCT scanner on the ability of examiners to identify the presence of simulated lesions of apical periodontitis. The authors found no significant difference in the sensitivity and specificity of the small volume CBCT scanner in the detection of simulated apical periodontitis, whether the degree of rotation of the X-ray source was $360^{\circ}$ (manufacturer's settings) or $180^{\circ}$. However, the scan time and therefore the exposure time and effective patient dose could expect to be halved with the lower degree of rotation (29).

The outcome of endodontic treatment can be expected to be better when the treatment is carried out prior to the development of signs of apical periodontitis on conventional radiographs (49). Cone beam computed tomography may prove a useful adjunct to the diagnosis of periapical disease associated with endodontic infection, especially when clinical signs and symptoms and conventional radiographic evidence prove inconclusive $(24,50)$. Earlier detection of apical periodontitis can be expected, with potentially better anticipated outcomes for non-surgical root canal treatment.

\section{Assessment of Potential Surgical Sites}

Cone beam computed tomography has been highlighted as an extremely useful tool in the planning of surgical endodontic treatment $(51,52)$. The spatial relationship of the specific root(s) undergoing the surgical procedure (and the associated bony destruction) can be accurately related to adjacent anatomical structures such as the maxillary sinuses, the inferior dental nerve canal and the mental foramen $(39,53)$. By arming themselves with this information, clinicians can assess the appropriateness of individual cases for treatment. Identifying and excluding unsuitable cases can reduce surgical morbidity. In cases deemed appropriate for treatment, accurate preoperative measurements that are relevant to the surgical procedure (e.g. root length and angulation, thickness of the cortical plate, root-end to mental foramen distance) can be made and applied to the surgical site during treatment, thereby enhancing case management and reducing the potential for iatrogenic damage (Fig. 3).

\section{Assessment and Management of Dental Trauma}

The benefits of CBCT in the assessment and management of dento-alveolar trauma have been highlighted in the literature $(54,55)$. The exact nature and extent of the injuries to the teeth and the alveolar bone can be assessed accurately by eliminating anatomical noise and image compression, thereby allowing appropriate treatment to be confidently implemented. The degree and direction of displacement associated with luxation injuries can be evaluated easily using CBCT (56) (Fig. 4). Furthermore, CBCT has been shown to be far more sensitive than multiple periapical radiographs in the detection of horizontal root fractures (57) (Fig. 5). Failure to identify the presence of root fractures following dental trauma may lead to inappropriate treatment and poorer prognoses for these teeth.
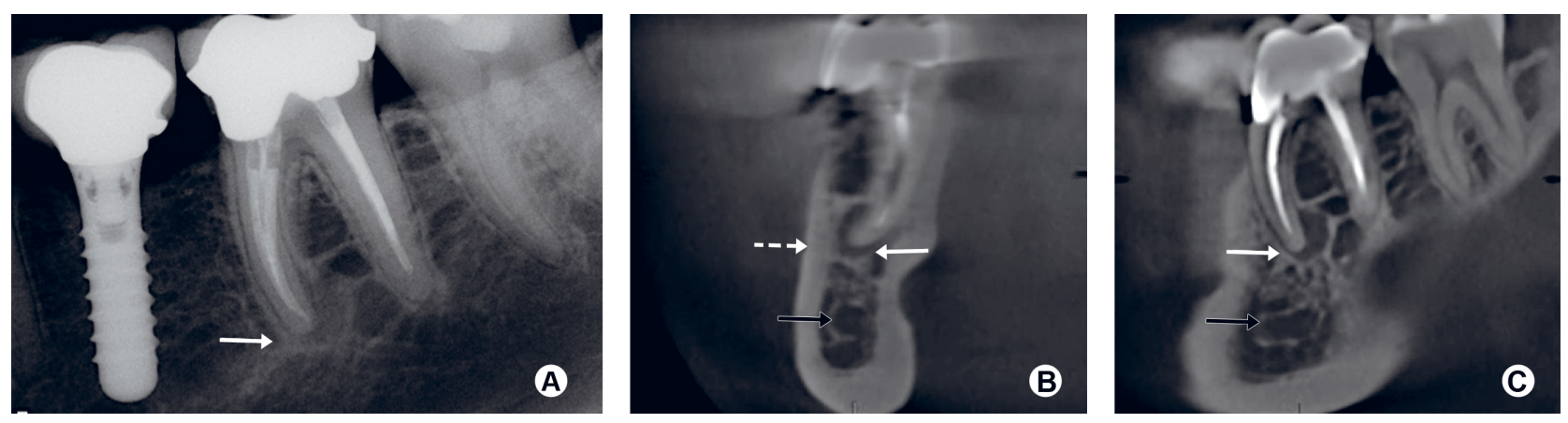

Figure 3. (a) Periapical radiograph of a mandibular left first molar tooth. The tooth has remained symptomatic and there is radiographic evidence of persistent apical periodontitis (solid white arrow) one year after non-surgical root canal treatment. (b,c) Coronal (b) and sagittal (c) CBCT slices through the same tooth. The spatial relationship of the mesial root-end (solid white arrows) to the buccal cortical plate (dashed white arrow) and the inferior dental canal (black arrows) can be assessed and measured accurately prior to apical root-end surgery. 
Single teeth are rarely traumatized in isolation. Small volume CBCT scanners, which are the most appropriate for the assessment of endodontic problems, capture all teeth and surrounding anatomy in a $4 \mathrm{~cm} \times 4 \mathrm{~cm}$
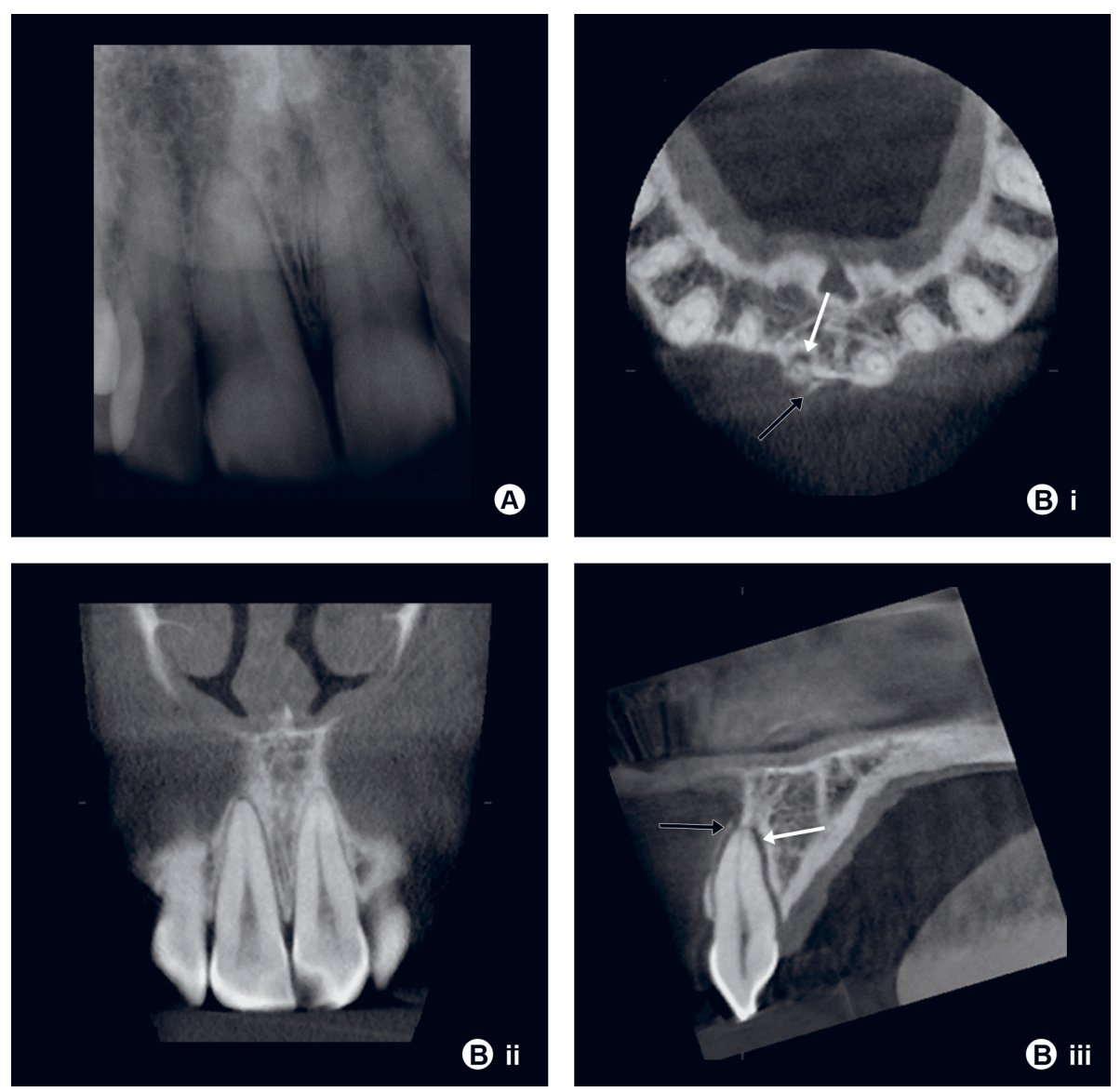

Figure 4. (a) Periapical radiograph of a luxated maxillary right central incisor tooth, following a traumatic dental injury. The radiograph reveals little about the nature and extent of the injury. (b) Axial (i), coronal (ii) and sagittal (iii) CBCT slices through the injured tooth The crown of the tooth has been luxated palatally resulting in the labial displacement of the root of the tooth through the buccal cortical plate (black arrows). This has resulted in a widening of the periodontal ligament space on the palatal aspect of the root (white arrows).
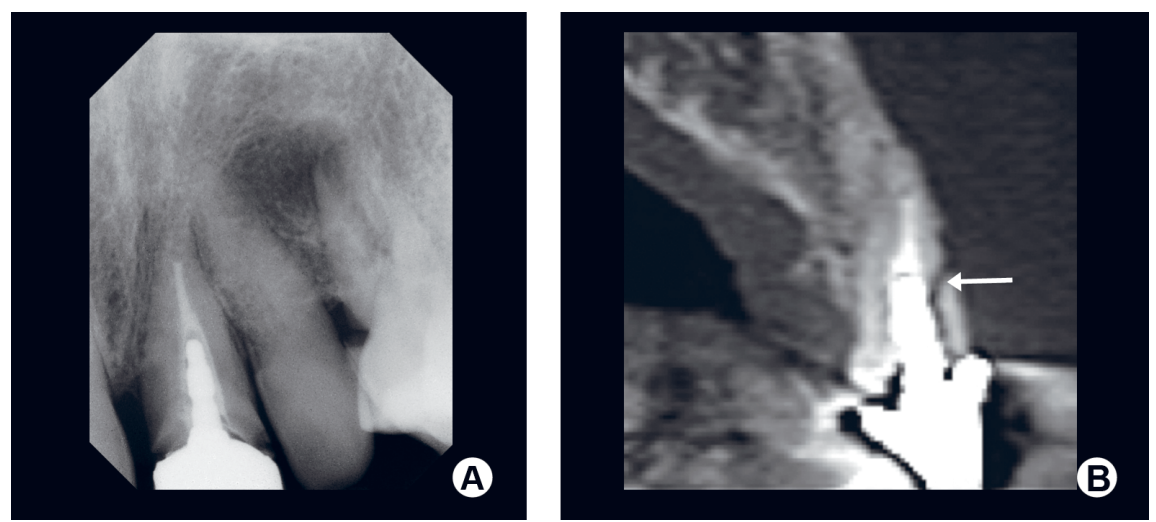

Figure 5. (a) Periapical radiograph of a maxillary left central incisor tooth restored with an ill-fitting crown retained by a cast post and core. There is no evidence of a root fracture on the radiograph. (b) Sagittal CBCT slice through the same tooth. A horizontal root fracture (arrow) is clearly evident. (Images courtesy of Steve Jones; Pentangle Specialist Dental Practice, Newbury, Berkshire, UK). 
FOV. Therefore, multiple teeth can be assessed without geometric distortion in a single scan. Furthermore, as $\mathrm{CBCT}$ is an extraoral imaging modality patient comfort is enhanced during the imaging process. This is particularly pertinent in the assessment of dental trauma where patient difficulty in accommodating bulky film holders and image receptors for conventional imaging is exacerbated by potentially mobile teeth and painful oral and dental tissues. Given that peak incidences of traumatic dental injuries (TDI) have been recorded at the ages of three and nine (58) patient comfort at the dental surgery following dental trauma is important from an emotional viewpoint.

External root resorption is a common complication after dental luxation $(59,60)$ and avulsion (61-63) injuries. Of the three types of ERR described by Andreasen, external inflammatory root resorption
(EIRR) is the only one which is responsive to endodontic treatment. The prevalence of EIRR following luxation injuries, regardless of the specific type, ranges from almost $5 \%$ (60) to $18 \%$ (64). It affects $30 \%$ of replanted avulsed teeth (63). EIRR is the most common form of ERR following luxation and avulsion injuries (64). Diagnosis of EIRR is based solely on the radiographic demonstration of the process $(18,61)$. The process can have a rapid onset and aggressive progression, such that complete resorption of an entire root can occur within 3 months. The diagnosis of EIRR at an early stage following TDI is, therefore, critical to the survival of the affected tooth. Durack et al. (3) using an ex vivo human model demonstrated that the sensitivity and specificity of CBCT in the detection simulated, incipient EIRR lesions is significantly superior to parallax periapical radiographs. The authors also reported that reducing
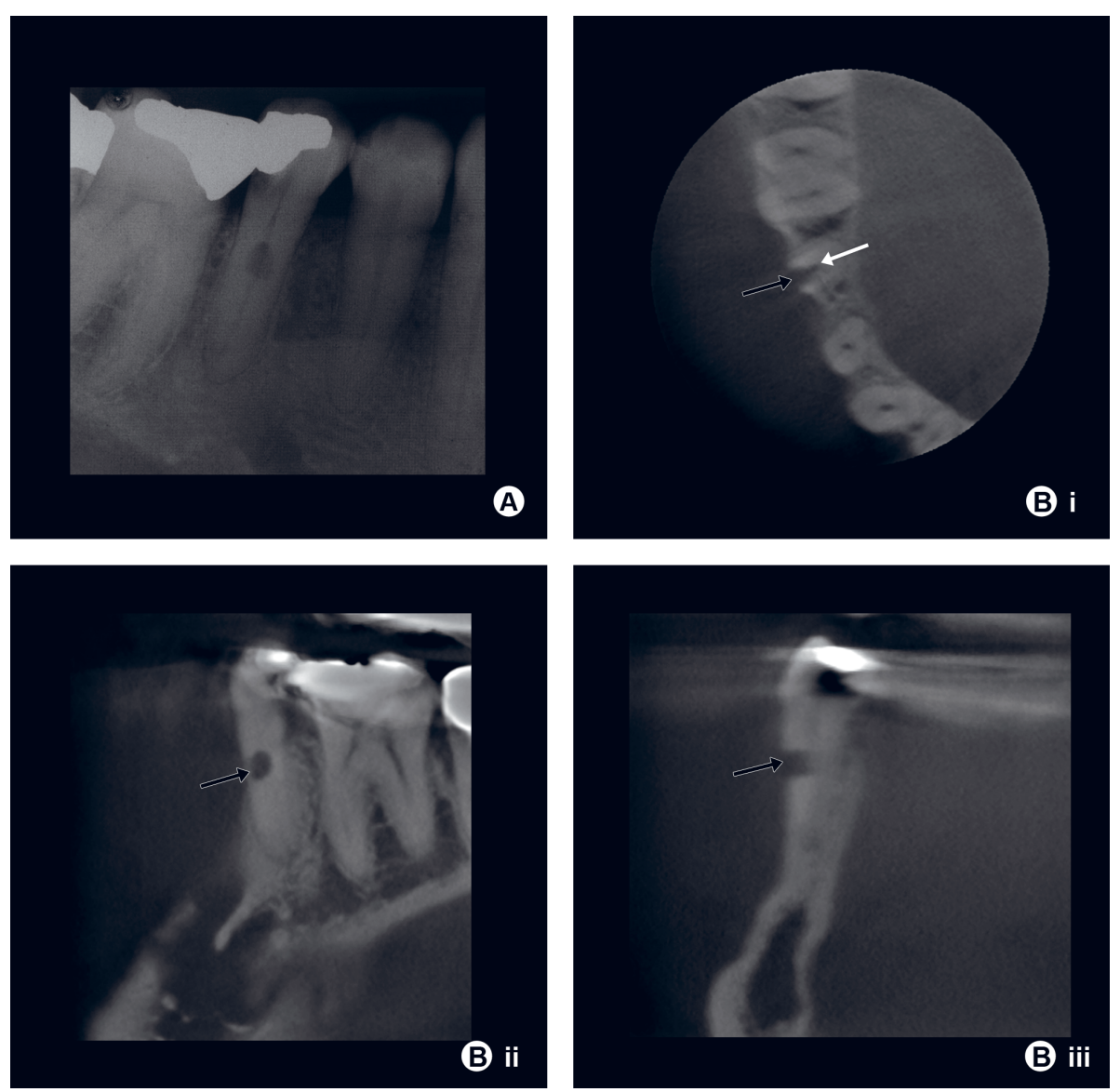

Figure 6. (a) Periapical radiograph of a mandibular second premolar tooth, which appears to be affected by root resorption. It is unclear from the radiograph whether the root resorption is internal or external or if the resorptive process has perforated the root canal wall. (b) Axial (i), coronal (ii) and sagittal (iii) CBCT slices through the tooth in the area of interest. It is clear form the CBCT images that the resorption originated on the external surface of the root (black arrows) and has perforated the root canal wall. The root canal shows no signs of ballooning enlargement associated with internal resorption (white arrow). 
the degree of rotation of the X-ray source from $360^{\circ}$ to $180^{\circ}$, and thereby halving the patient's effective radiation dose, did not impair the diagnostic yield of the imaging system. If the resorption can be diagnosed early and the tooth can be treated promptly then the prognosis of the tooth will naturally be enhanced. If, however, the resorption progresses unnoticed, until it becomes evident on conventional images, significant damage may already have occurred to the tooth. Traumatic dental injuries represent the only clinical scenarios where CBCT could possibly be justified to assess teeth for the presence of external resorption, before the process becomes apparent on conventional radiographs. This would be part of an overall assessment of the injuries to the traumatized teeth. Currently CBCT is often used to examine the extent of certain types of ERR (e.g. pressure related (surface) resorption and external cervical resorption) and the prognosis of the affected tooth. In these cases, CBCT scans are always prescribed secondary to conventional radiographic findings, which is rarely at an early stage of the resorption process.

\section{Assessment of Root Canal Anatomy and Morphology}

Conventional radiographs frequently fail to disclose the number of canals in teeth undergoing nonsurgical root canal treatment $(65,66)$. Failure to identify and treat accessory canals can negatively influence treatment outcome (67). Matherne et al. (68) using an ex vivo human model demonstrated the superiority of CBCT over conventional radiography in detecting the presence of supplemental canals (Figs. 2 and 6). Conventional radiographs failed to identify at least one root canal in 4 out of 10 of the examined teeth. Tu et al. (65) reported a higher prevalence of distolingual roots in the mandibular first molar teeth of a Taiwanese population when they were assessed using CBCT (33\%) as compared to when conventional radiographs were used $(21 \%)$. Knowledge of the presence or absence of supplemental canals and roots prior to the commencement of treatment should lead to higher detection rates in the former and more conservative access cavity preparations in the latter.

Undetermined canal morphology enhances the possibility of peri-operative mishaps such as ledge formation, canal transportation or even perforation (69-71), potentially compromising the outcome of the treatment (72). Cone beam computed tomography has been shown to be a reliable tool to accurately assess the degree of curvatures associated with the roots of teeth with "normal" anatomical forms (73). The availability of this information preoperatively reduces the chances of the aberrations outlined above occurring. In addition, CBCT has proved a useful assessment and treatment planning tool when teeth with anatomical and morphological anomalies, such as dens invaginatus and fused teeth require endodontic treatment $(74,75)$.

\section{Diagnosis, Assessment and Management of Root Resorption}

The clinical diagnosis of root resorption relies on the radiographic demonstration of the process $(18,61,76)$. The sensitivity of conventional radiography is significantly poorer than CBCT in the detection of ERR in its early stages (3) and significant hard tissue damage
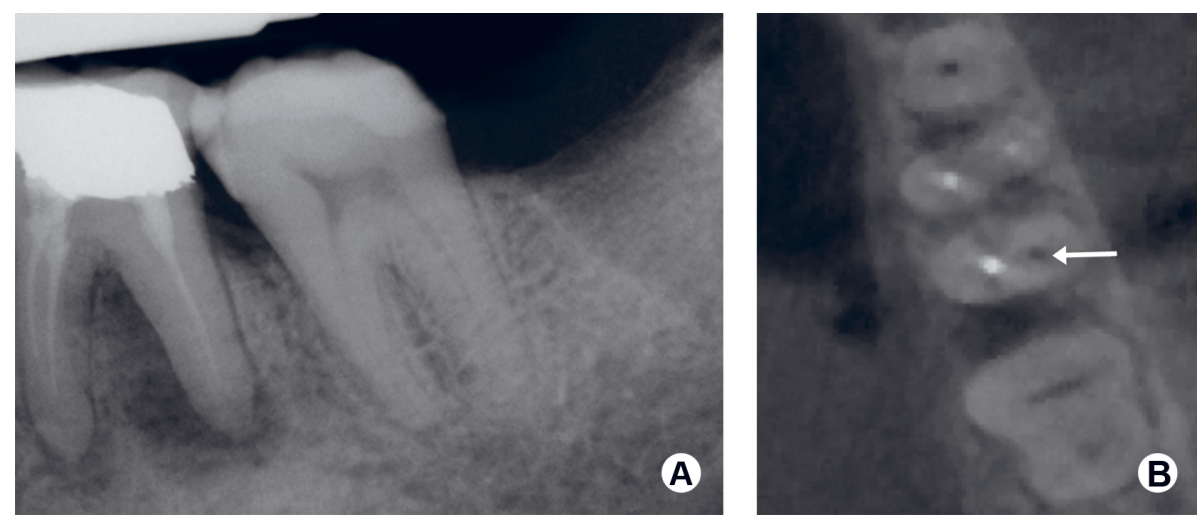

Figure 7. (a) Periapical radiograph of a mandibular left first molar tooth with a $10^{\circ}$ horizontal shift in the angle of the X-ray tube head. There is no evidence of a second distal canal on this image despite the oblique view taken. (b) Axial CBCT slice through the same tooth clearly demonstrating the presence of an uninstrumented distobuccal canal (white arrow). 
may have potentially occurred to the affected tooth before the resorption becomes evident on conventional radiographs. Furthermore, when a diagnosis of root resorption is made based on conventional radiographic findings it must be remembered that ERR superimposed on the root canal may mimic internal resorption (77). Differentiating between external cervical resorption (ECR) and internal resorption can be particularly difficult $(78,77)$ (Fig. 7).

Clinical studies directly comparing the ability of intraoral radiographs and CBCT to detect and assess the nature of root resorption are limited. One clinical study did report that $\mathrm{CBCT}$ is superior to conventional radiography in diagnosing and determining the extension of non-specific inflammatory resorption on root surfaces (79). Patel et al. (80), in a further clinical study, compared the accuracy of conventional intraoral radiography and $\mathrm{CBCT}$ in the diagnosis and management of external cervical and internal resorption lesions. The authors reported $\mathrm{CBCT}$ to be $100 \%$ accurate in the diagnosis of the presence and type of the root resorption and the overall sensitivity of intraoral radiographs was lower than CBCT.

These finding have been validated in ex vivo studies. Kamburoğlu et al. (81) assessed examiner ability to identify and differentiate between simulated ECR and simulated internal root resorption (IRR) at the cervical region of the root canal, using CBCT and conventional, periapical radiography. Cone bean computed tomography performed statistically better than intraoral periapical radiography in the detection and localization of the simulated resorption cavities. It was concluded that $\mathrm{CBCT}$ is an effective and appropriate method for identifying and differentiating between incipient, simulated ECR and IRR cavities, whilst conventional radiography is not.

\section{Diagnosis of Vertical Root Fractures}

Identifying the presence of vertical root fractures (VRF) is often an endodontic challenge (82). Clinical and radiographic evidence of the presence of root fractures does not always present itself until the fracture has been present for some time. However, even with longstanding VRF clinical signs of their existence maybe little more than a draining buccal sinus (83), which is certainly not pathognomonic of the problem. While a deep, isolated, thin periodontal pocket is suggestive of VRF (83), difficulty aligning the periodontal probe along the periodontal defect sometimes means this sign is missed. Radiographic features suggestive of VRF such as J-shaped and halo-shaped radiolucencies (83) do not appear until significant bone destruction has occurred and similarly shaped radiolucencies may manifest themselves in cases of apical periodontitis not associated with VRF.

Ex vivo studies have demonstrated that $\mathrm{CBCT}$ is more sensitive than conventional radiography in the detection of vertical fractures in roots (84). However, care should be taken when assessing root filled teeth for VRF using CBCT as scatter produced by the root filling or other high-density intraradicular material may incorrectly suggest the presence of a fracture (84).

\section{Assessment of the Outcome of Endodontic Treatment}

The ability of CBCT to detect the bony destruction associated with apical periodontitis before the damage is evident on conventional radiographs, is an encouraging discovery. The outcome of endodontic treatment can be expected to be better when it is executed prior to the development of conventional radiographic signs of the disease (49). However, this theory, while logical, is based on the assumption that the outcome of the treatment will be assessed using conventional radiographic methods. When the disease process is diagnosed using $\mathrm{CBCT}$ and the outcome of treatment is assessed using conventional radiographs a true appreciation of treatment outcome cannot be obtained. For a more accurate assessment of the outcome of root canal treatment using CBCT, preoperative scans and post-treatment review scans should be compared. There is limited data in the literature pertaining to the outcome of endodontic treatment using CBCT as the assessment tool, but that which exists suggests that the outcome of treatment may not be as favorable as it appears when conventional radiographs are used to assess outcome.

Paula-Silva et al. (45) compared CBCT and conventional periapical radiographs to assess the outcome of endodontic treatment in dogs. Six months after treatment, the success rate was deemed to be $79 \%$ when the teeth were assessed with conventional radiographs, while the success rate was $35 \%$ when CBCT was used to assess outcome.

In a clinical study comparing the outcome of endodontic treatment in humans, Liang et al. (85) reported the success rates to be $87 \%$ when the cases were assessed using periapical radiographs and $74 \%$ 
when $\mathrm{CBCT}$ was used. The review period was 2 years. In view of this evidence it is likely that many cases of apical periodontitis previously thought to have healed on conventional radiographs following root canal treatment may indeed have failed to resolve, in full. This may prompt a re-assessment of the very strict criteria currently applied to the radiographic evaluation of endodontic treatment success, which to date has been based on conventional imaging (86).

\section{CONCLUDING REMARKS}

This review paper highlights the potential uses of $\mathrm{CBCT}$ in the assessment and management of endodontic problems. This three-dimensional imaging technique overcomes the limitations of conventional radiography and is a beneficial adjunct to the endodontist's armamentarium.

Nevertheless, the effective radiation dose to patients when using CBCT is higher than in conventional intraoral radiography and any benefit to the patient of CBCT scans should outweigh any potential risks of the procedure, in order to be justified (87). The radiation should be as low as reasonably achievable (ALARA). The decision to prescribe CBCT scans in the management of endodontic problems must be made on a case-by-case basis and only when sufficient diagnostic information is not attainable from other diagnostic tests, be they clinical or radiographic.

\section{RESUMO}

Tomografia computadorizada de feixe cônico (CBCT, sigla em Inglês para cone beam computed tomography) é um moderno sistema radiológico de imagem idealizado especificamente para uso no esqueleto maxilofacial. Este sistema supera muitas das limitações da radiografia convencional, produzindo imagens não distorcidas e tridimensionais da área examinada. Tais propriedades tornam este método de imagem especialmente apropriado para a Endodontia. O profissional consegue obter uma visão melhor da região anatômica desejada, resultando em melhor detecção de doenças de origem endodôntica e um planejamento mais efetivo do tratamento. Além disso, o sistema utiliza doses de radiação significantemente menores em comparação à tomografia computadorizada convencional. O objetivo deste artigo é revisar a literatura atual relativa às limitações e possíveis aplicações da CBCT na prática endodôntica.

\section{ACKNOWLEDGEMENTS}

The authors would like to thank Steve Jones and Rob Oretti (Pentangle Specialist Dental Practice, Newbury, Berkshire, UK) for their permission to use the images in Figure 5.

\section{REFERENCES}

1. Patel S, Dawood A, Whaites E, Pitt Ford T. New dimensions in endodontic imaging: Part 1. Conventional and alternative radiographic systems. Int EndodJ 2009;42:447-462.

2. Cotti E, Campisi G. Advanced radiographic techniques for the detection of lesions in bone. Endod Topics 2004;7:52-72.

3. Durack C, Patel S, Davies J, Wilson R, Mannocci F. Diagnostic accuracy of small volume cone beam computed tomography and intraoral periapical radiography for the detection of simulated external inflammatory root resorption. Int Endod J 2011;44:136147.

4. Silva JA, Alencar AH, Rocha SS, Lopes LG, Estrela C. Threedimensional image contribution for evaluation of operative procedural errors in endodontic therapy and dental implants. Braz Dent J 2012;23:127-134

5. Webber RL, Messura JK. An in vivo comparison of digital information obtained from tuned-aperture computed tomography and conventional dental radiographic imaging modalities. Oral Surg Oral Med Oral Pathol Oral Radiol Endod 1999;88:239-247.

6. Nance R, Tyndall D, Levin LG, Trope M. Identification of root canals in molars by tuned-aperture computed tomography. Int Endod J 2000;33:392-396.

7. Brynolf I. A histological and roentenological study of the periapical region of human upper incisors. Odontologisk Revy 1967;18:Supplement 11.

8. Forsberg J. Radiographic reproduction of endodontic 'working length' comparing the paralleling and the bisecting-angle techniques. Oral Surg Oral Med Oral Pathol Oral Radiol Endod 1987;64:353-360.

9. Forsberg J. A comparison of the paralleling and bisecting-angle radiographic techniques in endodontics. Int Endod J 1987;20:177182.

10. Forsberg J. Estimation of the root filling length with paralleling and bisecting-angle radiographic techniques performed by undergraduate students. Int Endod J 1987;20:282-286.

11. Whaites E. Periapical radiography. In: Essentials of Dental Radiology and Radiography. Whaites E (Editor). $4^{\text {th }}$ ed. Churchill Livingston Elsevier; 2007.

12. Vande Voorde HE, Bjorndahl AM. Estimated endodontic "working length" with paralleling radiographs. Oral Surg Oral Med Oral Pathol 1969;27:106-110.

13. Revesz G, Kundel HL, Graber MA. The influence of structured noise on the detection of radiologic abnormalities. Invest Radiol 1974;6:479-486.

14. Kundel HL, Revesz G. Lesion conspicuity, structured noise, and film reader error. Am J Roentgenol 1976;126:1233-1238.

15. Bender IB, Seltzer S, Soltanoff W. Endodontic success - a reappraisal of criteria Part I. Oral Surg Oral Med Oral Pathol 1966;22:780-789.

16. Bender IB, Seltzer S, Soltanoff W. Endodontic success - a reappraisal of criteria Part III. Oral Surg Oral Med Oral Pathol 1966;22:791-802.

17. Schwartz SF, Foster JK. Roentgenographic interpretation of experimentally produced bony lesions. Part 1 Oral Surg Oral Med Oral Pathol 1971;32:606-612.

18. Andreasen JO. Experimental dental traumatology: development of a model for external root resorption. Endod Dent Traumatol 1987;3:269-287.

19. Chapnick L. External root resorption: an experimental radiographic evaluation. Oral Surg Oral Med Oral Pathol 1989;67:578-582. 
20. Gröndahl H-G, Huumonen S. Radiographic manifestations of periapical inflammatory lesions. Endod Topics 2004;8:55-67.

21. Rudolph DJ, White SC. Film-holding instruments for intraoral subtraction radiography. Oral Surg Oral Med Oral Pathol 1988;65:767-772.

22. Arai Y, Tammisalo E, Iwai K, Hashimoto K, Shinoda K. Development of a compact computed tomographic apparatus for dental use. Dentomax Radiol 1999;28:245-248.

23. Mozzo P, Procacci C, Tacconi A, Martini PT, Andreis IA. A new volumetric $\mathrm{CT}$ machine for dental imaging based on the conebeam technique: preliminary results. Eur Radiol 1999;8:15581564.

24. Patel S. New dimensions in endodontic imaging: Part 2. Cone beam computed tomography. Int Endod J 2009;42:463-475.

25. Scarfe WC, Levin MD, Gane D, Farman AG. Use of cone beam computed tomography in endodontics. Int $\mathrm{J}$ Dent 2009;2009:634567.

26. ICRP Publication 103 (2007) Radiation protection. Recommendations of the International Commission on Radiological Protection. Pergamon Press.

27. Loubele M, Bogaerts R, Van Dijck E, Pauwels R, Vanheusden S, Suetens $\mathrm{P}$, et al.. Comparison between effective radiation dose of CBCT and MSCT scanners for dentomaxillofacial applications. Eur J Radiol 2009;71:461-468.

28. Gijbels F, Jacobs R, Sanderink G, De Smet E, Nowak B, Van Dam $\mathrm{J}$, et al.. A comparison of the effective dose from scanography with periapical radiography. Dentomax Radiol 2002;31:159-163.

29. Lennon S, Patel S, Foschi F, Wilson R, Davies J, Mannocci F. Diagnostic accuracy of limited volume cone beam computed tomography in the detection of periapical bone loss: $360^{\circ}$ scans versus $180^{\circ}$ scans. Int Endod J 2011;44:1118-1127.

30. Scarfe WC, Farman AG. What is cone-beam CT and how does it work? Dent Clin N Amer 2008;52:707-730.

31. Scarfe WC, Farman AG, Sukovic P. Clinical applications if conebeam computed tomography in dental practice. J Can Dent Assoc 2006;72:75-80.

32. Kobayashi K, Shimoda S, Nakagawa Y, Yamamoto A. Accuracy in measurement of distance using cone-beam computerized tomography. Int J Oral Maxillofac Surg 2004;19:228-231.

33. Murmulla R, Wörtche R, Mühling J, Hassfeld S. Geometric accuracy of the New Tom 9000 cone beam CT. Dentomax Radiol 2005;34:28-31

34. Hashimoto K, Arai Y, Iwai K, Araki M, Kawashima S, Terakado M. A comparison of a new limited cone beam computed tomography machine for dental use with a multidetector row helical CT machine. Oral Surg Oral Med Oral Pathol Oral Radiol Endod 2003;95:371-377.

35. Hashimoto K, Kawashima S, Araki M, Sawada K, AkiyamaY. Comparison of image performance between cone-beam computed tomography for dental use and four-row multidetector helical CT. J Oral Sci 2006;48:27-34.

36. Hashimoto K, Kawashima S, Kameoka S, Akiyama Y, Honjoya T, Ejima K, et al.. Comparison of image validity between cone beam computed tomography for dental use and multidetector row helical computed tomography. Dentomax Radiol 2007;36:465-471.

37. Bartling SH, Majdani O, Gupta R, Rodt T, Dullin C, Fitzgerald PF, et al.. Large scan field, high spatial resolution flat-panel detector based volumetric CT of the whole human skull base and for maxillofacial imaging. Dentomax Radiol 2007;36:317-327.

38. Roberts JA, Drage NA, Davies J, Thomas DW. Effective does from cone beam CT examinations in Dentistry. Br J Radiol 2009;82:3540 .

39. Lofthag-Hansen S, Huumonen S, Gröndahl K, Gröndahl H-G. Limited cone beam CT and intraoral radiography for the diagnosis of periapical pathology. Oral Surg Oral Med Oral Pathol Oral Radiol Endod 2007;103:114-119.

40. Estrela C, Bueno MR, Leles CR, Azevedo B, Azevedo JR. Accuracy of cone beam computed tomography and panoramic radiography for the detection of apical periodontitis. J Endod 2008:34:273-279.

41. Yamamoto K, Ueno K, Seo K, Shinohara D. Development of dento-maxillofacial cone beam X-ray computed tomography system. Orthod Craniofac Res 2003;6:160-162.

42. Farman AG, Farman TT. A comparison of 18 different X-ray detectors currently used in dentistry. Oral Surg Oral Med Oral Pathol Oral Radiol Endod 2005;99:485-489.

43. White S, Pharaoh M. Advanced imaging modalities. In: Oral Radiology: principles and interpretation. White S, Pharaoh M (Editors). 5th ed. St Louis, MO: Mosby.

44. Paula-Silva FWG, Júnior MS, Leonardo MR, Consolaro A, Silva LAB, Preto R. Cone-beam computerized tomographic, radiographic, and histological evaluation of periapical repair in dogs post-endodontic treatment. Oral Surg Oral Med Oral Pathol Oral Radiol Endod 2009;108:796-805.

45. Paula-Silva FWG, Hassam B, da Silva LAD, Leonardo MR, Wu $\mathrm{M}-\mathrm{K}$. Outcome of root canal treatment in dogs determined by periapical radiography and cone-beam computed tomography scans. J Endod 2009;35:723-726.

46. Low MTL, Dula KD, Bürgin W, von Arx T. Comparison of periapical radiography and limited cone-beam tomography in posterior maxillary teeth referred for apical surgery. J Endod 2008;34:557-562.

47. Patel S, Dawood A, Mannocci F, Wilson R, Pitt Ford T. Detection of periapical bone defects in human jaws using cone beam computed tomography and intraoral radiography. Int Endod J 2009; $42: 507-515$.

48. Stavropoulos A, Wenzel A. Accuracy of cone beam dental CT, intraoral digital and conventional film radiography for the detection of periapical lesions: an ex vivo study in pig jaws. Clin Oral Invest 2007;11:101-106.

49. Friedman S. Prognosis of initial endodontic therapy. Endod Topics 2002;2:59-98.

50. Sedentexct radiation protection: cone beam for dental and maxillofacial radiology. evidence based guidelines (v 2.0 Final); 2011: http://www.sedentexct.eu/files/guidelines final.pdf.

51. Rigolone M, Pasqualini D, Bianchi L, Berutti E, Bianchi SD. Vestibular surgical access to the palatine root of the superior first molar: "low-does cone-beam" CT analysis of the pathway and its anatomic variations. J Endod 2003;29:773-775.

52. Tsurumchi T, Honda K. A new cone beam computerized tomography system for use in endodontic surgery. Int Endod J 2007;40:224-232.

53. Patel S, Dawood A, Pitt Ford T, Whaites E. The potential applications of cone beam computed tomography in the management of endodontic problems. Int Endod J 2007;40:818830.

54. Cohenca N, Simon JH, Roges R, Morag Y, Malfaz JM. Clinical indications for digital imaging in dento-alveolar trauma. Part 1: traumatic injuries. Dent Traumatol 2007;23:95-104.

55. Cotton TP, Geisler TM, Holden DT, Schwartz SA, Schindler WG Endodontic applications of cone-beam volumetric tomography. J Endod 2007;9:1121-1132.

56. Patel S, Durack C. Section 7. Case 7.2. Lateral luxation. In: Pitt Ford's Problem Based Learning in Endodontology. Patel S, Duncan HF (Editors). $1^{\text {st }}$ ed. Chichester: Wiley Blackwell, 256263.

57. Kamburoğlu K, Cebeci AR, Gröndahl HG. Effectiveness of limited cone-beam computed tomography in the detection of horizontal 
root fracture. Dent Traumatol 2009;25:256-261

58. Andreasen JO, Ravn JJ. Epidemiology of traumatic dental injuries to primary and permanent teeth in a Danish population sample. Int J Oral Surg 1972;1:235-239.

59. Andreasen JO. Luxation of permanent teeth due to trauma. A clinical and radiographic follow-up of 189 injured teeth. Scand J Dent Res 1970;78:273-286.

60. Andreasen FM, Vestergaard Pedersen B. Prognosis of luxated permanent teeth - the development of pulp necrosis. Endod Dent Traumatol 1985;1:207-220.

61. Andreasen JO, Hjørting-Hansen E. Replantation of teeth. I. Radiographic and clinical study of 110 human teeth replanted after accidental loss. Acta Odontol Scand 1966;24:263-286.

62. Andreasen JO, Hjørting-Hansen E. Replantation of teeth. II Histological study of 22 replanted anterior teeth in humans. Acta Odontol Scand 1966;24:287-306.

63. Andreasen JO, Borum MK, Jacobsen HL, Andreasen FM. Replantation of 400 avulsed permanent incisors. 1. Diagnosis of healing complications. Endod Dent Traumatol 1995;11:51-58.

64. Crona-Larsson G, Bjarnasan S, Norén JG. Effect of luxation injuries on permanent teeth. Endod Dent Traumatol 1991;7:199206.

65. Tu M-G, Tsai C-C, Jou M-J, Chen W-L, Chang Y-F, Chen S-Y, et al.. Prevalence of three-rooted mandibular first molars among Taiwanese individuals. J Endod 2007;33:1163-1166.

66. Zheng Q, Xue-dong Z, Jiang Y, Sun T, Liu C, Xue H, et al. Radiographic investigation of frequency and degree of canal curvatures in Chinese mandibular permanent incisors. J Endod 2009;35:175-178.

67. Wolcott J, Ishley D, Kennedy W, Johnson S, Minnich S, Meyers $\mathrm{J}$. A 5 year clinical investigation of second mesiobuccal canals in endodontically treated and retreated maxillary molars. J Endod 2005;31:262-264.

68. Matherne RP, Angelopoulos C, Kulilid JC, Tira D. Use of conebeam computed tomography to identify root canal systems in vitro. J Endod 2008;34:87-89.

69. Weine FS, Kelly RF, Bray KE. Effect of preparation with endodontic handpieces on original canal shape. J Endod 1976;2:298-303.

70. Mullaney TP. Instrumentation of finely curved canals. Dent Clin N Amer 1979;23:575-592.

71. Roane JB, Sabala CL, Duncanson MG. The balanced force concept for instrument - ation of curved canals. J Endod 1985;11:203-211.

72. Zheng Q, Xue-dong Z, Jiang Y, Sun T, Liu C, Xue H, et al. Radiographic investigation of frequency and degree of canal curvatures in Chinese mandibular perma - nent incisors. J Endod 2009;35:175-178.

73. Estrela C, Bueno MR, Sousa-Neto MD, Pécora JD. Method for determination of root curvature radius using cone-beam computed tomography images. Braz Dent J 2008;19:114-118.

74. Patel S. The use of cone beam computed tomography in the conservative management of dens invaginatus: a case report. Int Endod J 2010;43:707-713.

75. Durack C, Patel S. The use of cone beam computed tomography in the management of dens invaginatus affecting a strategic tooth in a patient affected by hypodontia: a case report. Int Endod J 2011;44:474-483.

76. Andreasen JO, Andreasen FM. Root resorption following traumatic dental injuries. Proc Finn Dent Soc 1991;88:95-114.

77. Patel S, Ricucci D, Durack C, Tay F. Internal root resorption: a review. J Endod 2010;36:1107-1121.

78. Gulabivala K, Searson LJ. Clinical diagnosis of internal resorption: an exception to the rule. Int Endod J 1995;28:255-260.

79. Estrela C, Reis Bueno M, Alencar AHG, Mattar R, Neto JV, Azevedo BC, et al.. Method to evaluate inflammatory root resorption by using cone beam computed tomography. J Endod 2009;35:1491-1497.

80. Patel S, Dawood A, Wilson R, Horner K, Mannocci F. The detection and management of root resorption lesions using intraoral radiography and cone beam computed tomography - an in vivo investigation. Int Endod J 2009;42:831-838.

81. Kamburoğlu K, Kurșun S, Yüksel S, Oztaş B. Observer ability to detect ex vivo simulated internal or external cervical root resorption. J Endod 2011;37:168-175.

82. Tamse A, Fuss Z, Lustig J, Kaplavi J. An evaluation of endodontically treated vertically fractured teeth. J Endod 1999;25:506-508.

83. Tamse A, Kaffe I, Lustig J, Ganor J, Fuss Z. Radiographic features of vertically fractured endodontically treated mesial roots of mandibular molars. Oral Surg Oral Med Oral Pathol Oral Radiol Endod 2006;101:797-802.

84. Hassan B, Metska ME, Ozok AR, va der Stelt P, Wesselink PR Detection of vertical root fractures in endodontically treated teeth by a cone beam computed tomography scan. J Endod 2009;35:719722.

85. Liang Y-H, Li G, Wesselink PR, Wu M-K. Endodontic outcome predictors identified with periapical radiographs and cone-beam computed tomography scans. J Endod 2011;37:326-331.

86. European Society of Endodontology. Quality guidelines for endodontic treatment: consensus report of the. Int Endod J 2006;39:921-930.

87. Farman AG. ALARA still applies-Editorial. Oral Surg Oral Med Oral Pathol Oral Radiol Endod 2005;100:395-397.

Received May 2, 2012 Accepted June 10, 2012 